Article

\title{
Application of Extension Sliding Mode Strategy to Maximum Power Point Tracking in Human Power Generation Systems
}

\author{
Meng-Hui Wang ${ }^{\dagger}$, Her-Terng Yau $*$ and Wei-Jhe Jiang ${ }^{\dagger}$ \\ Department of Electrical Engineering, National Chin-Yi University of Technology, 35, 215 Lane, \\ Section 1, Chung Shan Road, Taiping, Taichung City 41170, Taiwan; \\ E-Mails: wangmh@ncut.edu.tw (M.-H.W.); f127860@gmail.com.tw (W.-J.J.)
}

$\dagger$ These authors contributed equally to this work.

* Author to whom correspondence should be addressed;

E-Mails: pan1012@ms52.hinet.net or htyau@ncut.edu.tw;

Tel.: +886-04-2392-4505 (ext. 7229); Fax: +886-04-2393-0062.

Academic Editor: Chien-Hung Liu

Received: 16 June 2015 / Accepted: 30 July 2015 / Published: 5 August 2015

\begin{abstract}
Sliding mode strategy (SMS) for maximum power point tracking (MPPT) is used in this study of a human power generation system. This approach ensures maximum power at different rotation speeds to increase efficiency and corrects for the lack of robustness in traditional methods. The intelligent extension theory is used to reduce input saturation and high frequency switching in sliding mode strategy, as well as to increase the efficiency and response speed. The experimental results show that the efficiency of the extension SMS (ESMS) is $5 \%$ higher than in traditional SMS, and the response is $0.5 \mathrm{~s}$ faster.
\end{abstract}

Keywords: human power generation system; sliding mode strategy; maximum power point tracking; extension theory; brushless DC motor 


\section{Introduction}

In recent years, many countries around the world have been concentrating on the development of green energy. Human power generation systems, which are $\mathrm{CO}_{2}$ emission free, inexhaustible and the cleanest of all green energy, have become a topical subject. The human power generation system considered here consists of a brushless DC motor (BLDCM), a three-phase bridge rectifier and a power converter. The system uses kinetic energy to drive a permanent magnet BLDCM to generate three-phase $\mathrm{AC}$ voltage which is rectified by a full-wave rectifier. The DC voltage is transformed and exported by the DC converter which is a boost device [1-5] that can be used for the conversion of electrical energy from different permanent magnet BLDCM systems. In a human power generation system uneven manual pedaling may result in unstable power output. All generators have different nonlinear P-V characteristic curves at different rotation speeds, and each of these curves has a best maximum power operating point. No recent studies have been made that have resulted in an effective maximum power point tracking strategy for human power generation systems and currently constant voltage output is assumed.

However, many current studies have been made of maximum power point tracking strategy for other kinds of new energy applications. These include P\&O [6] and Extremum Seeking Control (ESC) [7] which have the advantage of easy and cheap implementation. However, they are not robust and when a steady state is reached output is likely to be subject to perturbation and oscillation around the maximum power point due to external interference. To remedy perturbation at the maximum power point in a human powered system, we propose SMS for MPPT. The precept being that the maximum power point (MPP) condition of INC in the generator $\mathrm{P}-\mathrm{V}$ characteristic curve is $\partial P / \partial V=0$, and the sliding manifold is defined accordingly. The strategy includes two modes, approaching conditions and sliding conditions. In the approaching condition the system trajectory makes timely and effective contact with the sliding manifold. Sliding conditions confine the system to the sliding manifold and the MPP finally reaches the target point. If the operating point is on the left or right side of MPP, the operating point moves against the MPP, this mode operates the system at the MPP effectively. However, SMS is likely to result in high frequency switching or signal input saturation that introduces high frequency noise. This noise can shorten converter and switch life and many studies have been made that propose solutions, including fuzzy theory [8] and extension theory [9]. In this study the extension theory has been applied to effectively avoid the shortcomings of high frequency SMS switching, minimize input saturation, and increase the efficiency of both energy conversion and response time.

\section{Equivalent Dynamic Mathematical Model of BLDCM}

The human power generation system uses a three-phase BLDCM. The generator equivalent circuit is shown in Figure 1 [10]. The Resistance of the Coil is $R s$; the self-Inductance of the Coil and Mutual Inductor of the Coil are $L$ and $M ; e_{a}, e_{b}$ and $e_{c}$ represent the electromotive reaction of the generator; $i_{a}, i_{b}$ and $i_{c}$ represent the phase current; $v_{a}, v_{b}$ and $v_{c}$ are the terminal voltages. The dynamic equation of the three-phase BLDCM is expressed as follows: [11] 


$$
\left[\begin{array}{l}
V_{a} \\
V_{b} \\
V_{c}
\end{array}\right]=\left[\begin{array}{l}
e_{a} \\
e_{b} \\
e_{c}
\end{array}\right]-\left[\begin{array}{ccc}
R_{s} & 0 & 0 \\
0 & R_{s} & 0 \\
0 & 0 & R_{s}
\end{array}\right]\left[\begin{array}{l}
i_{a} \\
i_{b} \\
i_{c}
\end{array}\right]-\left[\begin{array}{lll}
L-M & 0 & 0 \\
0 & L-M & 0 \\
0 & 0 & L-M
\end{array}\right] \frac{d}{d t}\left[\begin{array}{l}
i_{a} \\
i_{b} \\
i_{c}
\end{array}\right]
$$

The magnetic flux density distribution of the driven BLDCM in the air gap is a trapezoidal wave as shown in Figure 2.

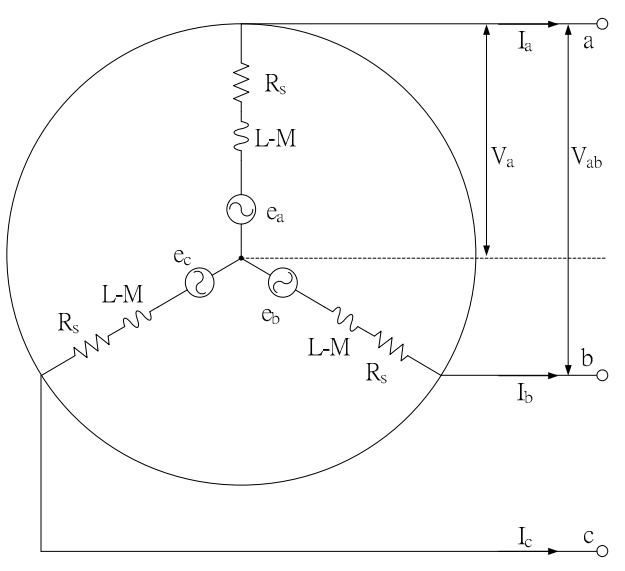

Figure 1. Generator equivalent circuit.

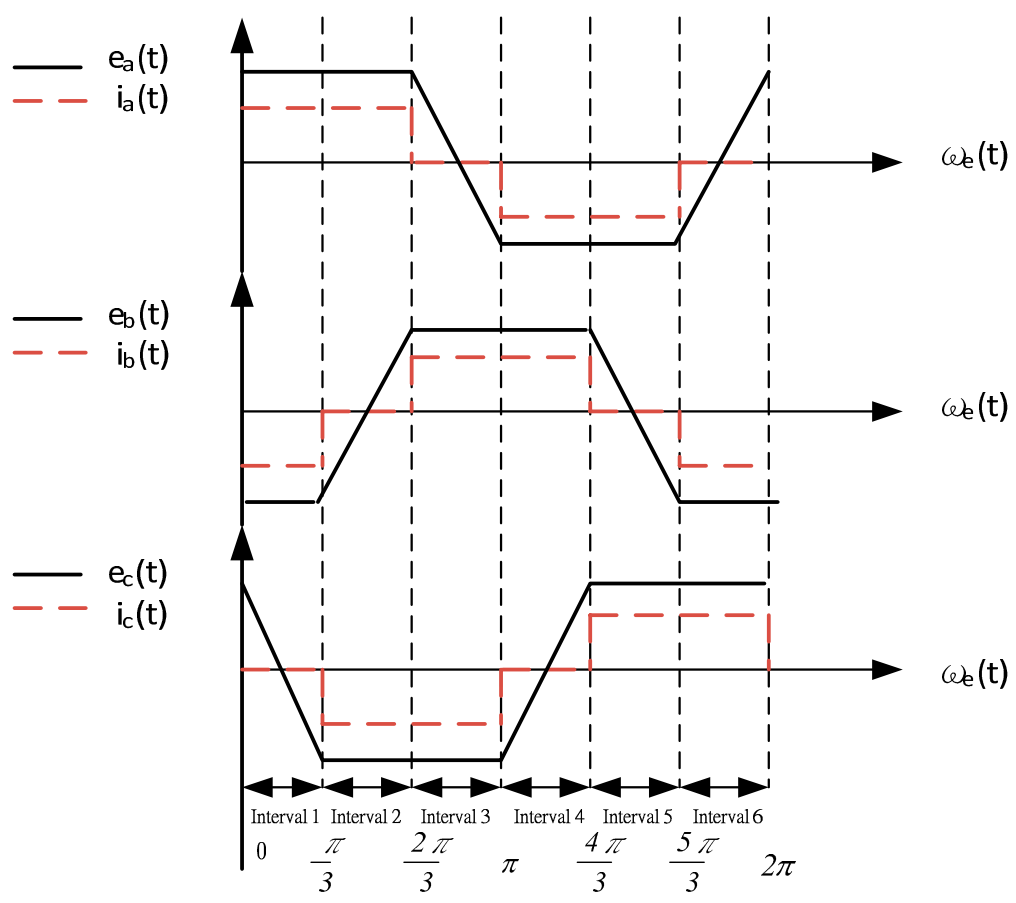

Figure 2. Three-phase rectifier circuit waveform timing diagram at fixed DC load.

The three-phase inner electric potential waveform in Figure 2 can be expressed as Equations (2) to (4), where $K_{g}$ is the generator inner electric potential constant; $\omega_{e}$ is the angular-rate of the rotor which is proportional to the mechanical rotation speed and pole of the generator; $\lambda$ is the magnetic flux linkage of the rotator side to stator side. The converter BLDCM power $P_{g}$ can be deduced from the three-phase bridge rectifier circuit waveform timing diagram at fixed DC load, expressed as Equation (5). 


$$
e_{a}=\left\{\begin{array}{c}
\frac{K_{g} \omega_{e} \lambda, 0 \leq \omega_{e} t \leq \frac{2 \pi}{3}}{\pi}\left(\omega_{e} t-\frac{5 \pi}{6}\right), \frac{2 \pi}{3} \leq \omega_{e} t \leq \pi \\
-K_{g} \omega_{e} \lambda, \pi \leq \omega_{e} t \leq \frac{5 \pi}{3} \\
\frac{6 K_{g} \omega_{e} \lambda}{\pi}, \frac{5 \pi}{3} \leq \omega_{e} t \leq 2 \pi \\
e_{b}\left(\omega_{e} t\right)=e_{a}\left(\omega_{e} t-\frac{2 \pi}{3}\right) \\
e_{c}\left(\omega_{e} t\right)=e_{a}\left(\omega_{e} t+\frac{2 \pi}{3}\right) \\
P_{g}=e_{a} i_{a}+e_{b} i_{b}+e_{c} i_{c}
\end{array}\right.
$$

The relationship between the generator inner electric potential and converter control current is observed, the BLDCM three-phase commutation sequence $S_{a}(t), S_{b}(t), S_{c}(t)$ can be defined by Equations (6) to (8) [12]:

$$
\begin{gathered}
S_{a}(t)=\sum_{n=0}^{\infty}\left[u\left(\omega_{e} t-2 n \pi\right)-u\left(\omega_{e} t-\frac{2 \pi}{3}-2 n \pi\right)-u\left(\omega_{e} t-\pi-2 n \pi\right)+u\left(\omega_{e} t-\frac{5 \pi}{3}-2 n \pi\right)\right] \\
S_{b}(t)=S_{a}\left(t-\frac{2 \pi}{3 \omega_{e}}\right) \\
S_{c}(t)=S_{a}\left(t-\frac{4 \pi}{3 \omega_{e}}\right)
\end{gathered}
$$

where $\mathrm{u}(t)$ is the unit step function, and $\mathrm{n}$ is an integer. The three-phase current distribution is observed, the equivalent DC armature current $i_{e q}(t)$ of the BLDCM is defined by Equation (9).

$$
\begin{gathered}
i_{e q}(t)=\frac{1}{2}\left[S_{a}(t) S_{b}(t) S_{c}(t)\right]\left[i_{a}(t) i_{b}(t) i_{c}(t)\right]^{T} \\
V_{e q}(t)=\frac{1}{2}\left[S_{a}(t) S_{b}(t) S_{c}(t)\right]\left[V_{a}(t) V_{b}(t) V_{c}(t)\right]^{T}
\end{gathered}
$$

The equivalent DC inner electric potential $e_{e q}$ and transfer power $P_{m}$ of the BLDCM can be deduced from Equations (2) to (5) and (9) and (10), expressed as follows:

$$
\begin{gathered}
e_{e q}=K_{g} \omega_{e} \lambda \\
P_{g}=K_{g} \omega_{e} \lambda i_{e q}
\end{gathered}
$$

The equivalent DC dynamics equation of the BLDCM can be obtained by substituting Equations (9) to (12) in Equation (1), and the dynamics equation is expressed by Equation (13). 


$$
V_{e q}=e_{e q}-R_{s} i_{e q}-(L-M) \frac{d i_{e q}}{d t}
$$

According to the above mathematical model, the human powered generator can be simulated using PSIM, the P-V characteristics curves at different rotation speeds is shown in Figure 3.

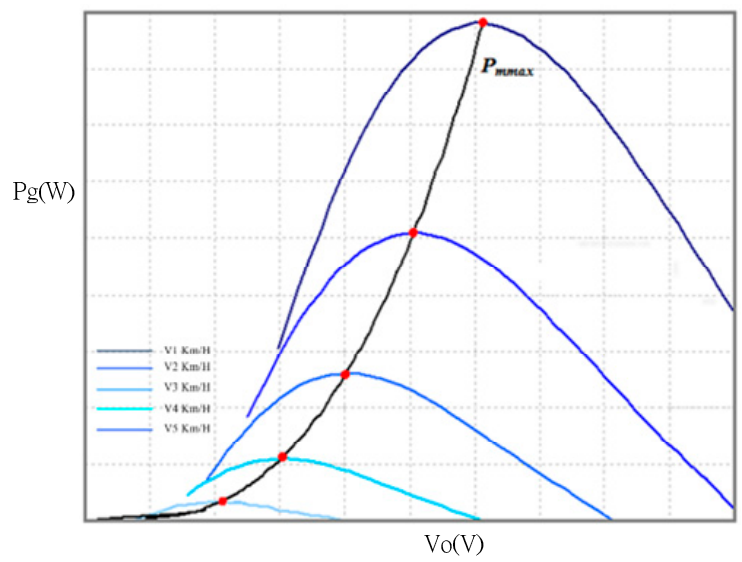

Figure 3. Characteristics curves of an exercise bike generator.

As can be seen, the pedal powered exercise bike generates different MPPs at different speeds. The design of a controller to enable operation at MPP at different rotational speeds is a topic of some importance.

\section{Boost Converter Design}

The boost converter of the system consists of an inductance, a capacitor, a diode, and switch components. The human power generation system architecture is shown in Figure 4. The converter switch employs pulse width modulation (PWM) control to boost the voltage [13].

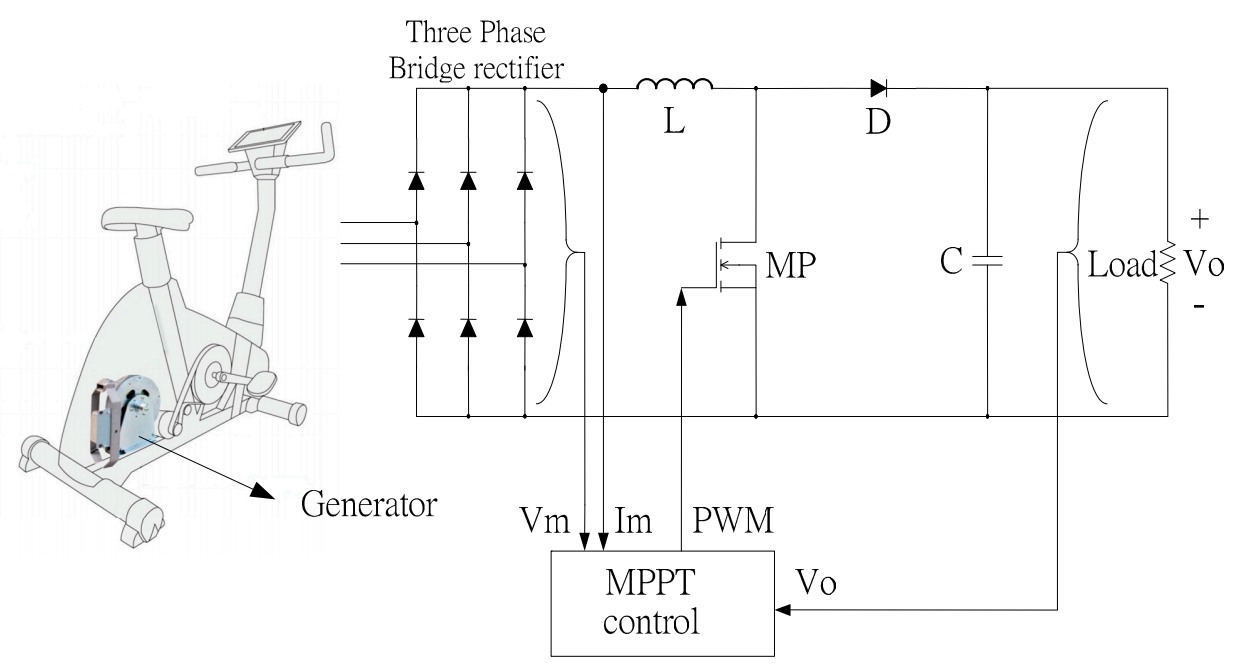

Figure 4. Human power generation system architecture.

Figure 5 shows the time variation over one cycle, and the switching voltage and inductance current duty cycle ratio. As can be seen in the figure it is assumed that the current is kept constant in the steady state, and the diode and switch have no voltage drop. Therefore, when the switch is on, the terminal 
voltage is $V_{m}$, with the switch off the terminal voltage is $V_{o} . V_{m}$ is the input voltage of the generator terminal after three-phase bridge rectification, and $V_{m}=V_{e q}$. The output voltage is expressed by Equation (14), where $t_{o n}$ is on, $t_{\text {off }}$ is off, and one cycle time is $T=t_{o n}+t_{\text {off, }}$, to give Equation (10).

$$
0=\int_{o n} V_{m} d t+\int_{o f f}\left(V_{m}-V_{o}\right) d t V_{m} t_{o n}+\left(V_{m}-V_{o}\right) t_{o f f}=0
$$

Equation (14) is rearranged to obtain the output voltage and input voltage duty cycle ratio $D=\frac{t_{o n}}{T}$, expressed by Equation (15).

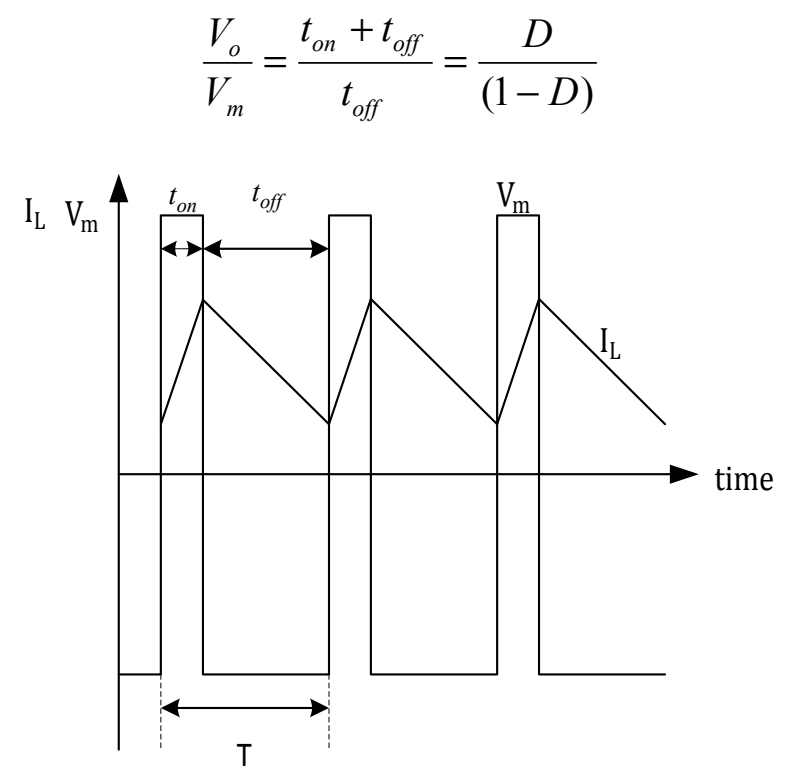

Figure 5. Switching voltage and duty cycle.

The boost converter has two states according to the switch MP on the state in Figure 4.

State 1:

In Figure 4, when the switch MP is turned on, the diode $D$ is turned off, and the input voltage flows directly through the inductance $L$. The inductance current $I_{L}$ rises, and the output end depends on capacitor $C$ which supplies energy to the load. The current $I_{L}$ flows through the switch to form a loop. The current and voltage Equations (16) and (17) are shown below:

$$
\begin{gathered}
\dot{I}_{L\left(M P_{-} o n\right)}=\frac{V_{m}}{L} \\
\dot{V}_{o\left(M P_{-} o n\right)}=-\frac{V_{o}}{C R}
\end{gathered}
$$

State 2:

When the switch MP is turned off (see Figure 4), the diode $D$ is turned on, and the energy stored in the inductance $L$ is released to the output end. In other words, $I_{L}$ decreases to zero current, and the switch MP and diode $D$ then enter the cut-off state. The current and voltage equations are expressed as Equations (18) and (19). 


$$
\begin{gathered}
\dot{I}_{L\left(M P_{-} o f f\right)}=\frac{V_{m}}{L}-\frac{V_{o}}{L} \\
\dot{V}_{o\left(M P_{-} o f f\right)}=-\frac{V_{o}}{C R_{L}}
\end{gathered}
$$

According to Equations (16) to (19), the numerical average rule is substituted in the dynamics Equation (20), $X_{1}=\left[\begin{array}{ll}I_{L\left(M P_{-} o n\right)} & V_{o\left(M P_{-} o n\right)}\end{array}\right]$ and $X_{2}=\left[\begin{array}{ll}I_{L\left(M P_{-} o f f\right)} & V_{o\left(M P_{-} o f f\right)}\end{array}\right]$ are defined and Equations (21) and (22) are obtained. The duty cycle ratio $U \in\left[\begin{array}{ll}0 & 1\end{array}\right]$ can be used to control the switch conduction time.

$$
\begin{gathered}
X=U X_{1}+(1-U) X_{2} \\
I_{L}=(U-1) \frac{V_{o}}{L}+\frac{V_{m}}{L} \\
V_{o}=(1-U) \frac{I_{L}}{C}+\frac{V_{o}}{C R}
\end{gathered}
$$

The SMS concept is applied to the design of the duty cycle $U$ to control the switch conduction time, so that the system can generate power at the MPPT at any rotation speed.

\section{Controller Design}

The sliding mode was first discovered by Russian investigators and has made a significant contribution to the design of multiple system controllers. The first control step [14,15], is the designation of the sliding manifold and then a control rule is established that allows the system state to be attracted to the sliding manifold without deviating from it. The system at MPP must satisfy $\frac{\partial P_{m}}{\partial V_{m}}=0$, and Equation (23) can be obtained [16].

$$
\frac{\partial P_{m}}{\partial V_{m}}=\frac{\partial\left(I_{m} V_{m}\right)}{\partial V_{m}}=I_{m}+V_{m} \frac{\partial I_{m}}{\partial V_{m}}, \text { and }\left(P_{m}=P_{g}, I_{m}=I_{L}=i_{e q}, V_{m}=V_{e q}\right)
$$

In Equation (23), $P_{m}$ is the input power of the generator after three-phase bridge rectification (Figure 4), $V_{m}$ and $I_{m}$ are the input voltage and input current of power generation after rectification. According to Equation (23), the sliding manifold is defined by Equation (24):

$$
\frac{\partial P_{m}}{\partial V_{m}}=\frac{\partial\left(I_{m} V_{m}\right)}{\partial V_{m}}=I_{m}+V_{m} \frac{\partial I_{m}}{\partial V_{m}}, \text { and }\left(P_{m}=P_{g}, I_{m}=I_{L}=i_{e q}, V_{m}=V_{e q}\right)
$$

When the system is in a sliding condition, $S=0$, and the equation is expressed as (25).

$$
\frac{\partial P_{m}}{\partial V_{m}}=\frac{\partial\left(I_{m} V_{m}\right)}{\partial V_{m}}=I_{m}+V_{m} \frac{\partial I_{m}}{\partial V_{m}}, \text { and }\left(P_{m}=P_{g}, I_{m}=I_{L}=i_{e q}, V_{m}=V_{e q}\right)
$$

In Figure 6 it can be seen that the duty cycle ratio and operating voltage of the $S$ operation mode at MPP are correlated with $U(0 \leq U \leq 1)$. The control switch duty cycle is used to adjust the PWM for MPPT. When the system is in the sliding condition, $S=0$, expressed by Equation (26), and the equivalent control $U_{e q}$ of the sliding manifold is expressed by Equation (27) [15]. 


$$
\begin{aligned}
& S=\left[\frac{\partial S}{\partial X}\right]^{T}, X=\left[\frac{\partial S}{\partial X}\right]^{T}\left(f(X)+g(X) U_{e q}\right)=0 \\
& U_{e q}=\frac{\left[\frac{\partial S}{\partial X}\right]^{T} \bullet f(X)}{\left[\frac{\partial S}{\partial X}\right]^{T} \cdot g(X)}=-\frac{\frac{V_{m}\left(i_{L}\right)-V_{o}}{L}}{\frac{V_{o}}{L}}=1-\frac{V_{m}}{V_{o}}
\end{aligned}
$$

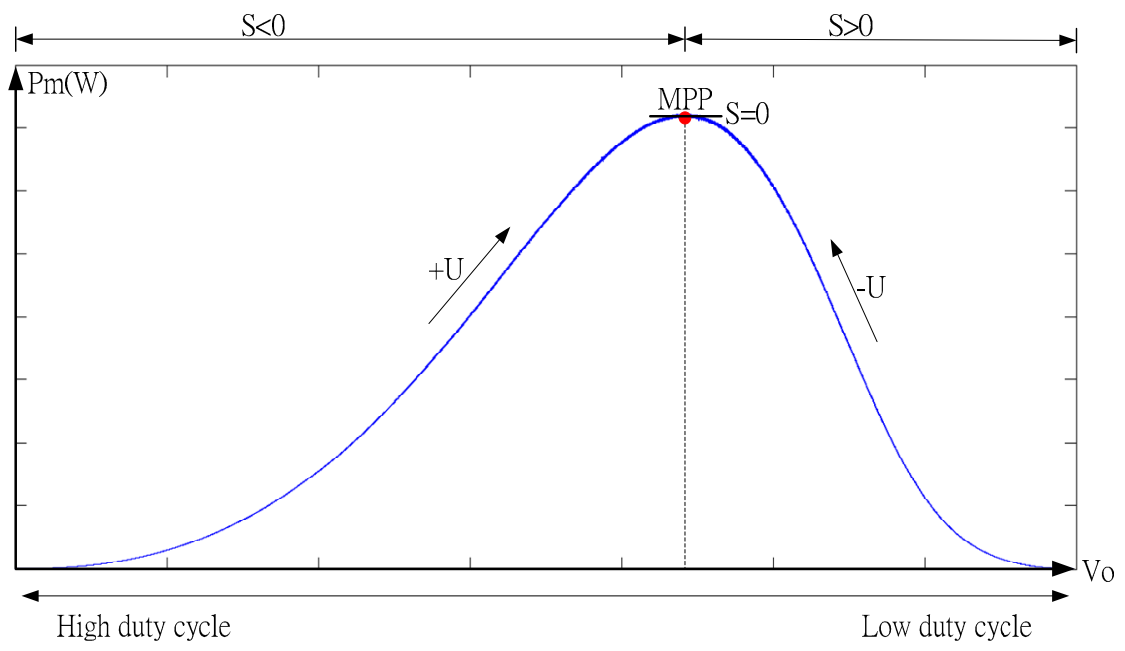

Figure 6. Duty cycle and operating voltage of MPPT.

According to Yau et al. [15], the appropriate switchover control law $U_{s w}=\sigma S$ is selected, in considering the controller saturation effect $\sigma>0$, the control law would be as in Equation (28).

$$
U=\left\{\begin{array}{c}
1, U_{e q}+\sigma S \geq 1 \\
U_{e q}+\sigma S, \text { for } 0 \leq U_{e q}+\sigma S<1 \\
0, U_{e q}+\sigma S \leq 0
\end{array}\right.
$$

According to Chu et al. and Yao et al. [14,15], the controller (28) enables the system to satisfy Lyapunov theory, expressed by Equation (29), and this proves the stability of SMS and MPPT control of the system.

$$
\dot{V}=S \dot{S}<0
$$

Also, according to Chu et al. and Yau et al. [14,15], to avoid the control input $U$ remaining in a saturated state $(U=0$ or 1$)$ for a long time, or being switched rapidly between two saturation values (which could affect the service life of the switch or cause high frequency switching noise) the value of parameter $\sigma$ should not be too large, $\sigma \leq 1 / R_{L}$ is recommended. Therefore, intelligent selection of the value of $\sigma$ so the controller will be $0<U<1$ is an important factor affecting performance. This will not only prolong component life and avoid faults, but will also reduce high frequency switching noise affecting converter output power $P_{o}$ and voltage $V_{o}$. Many recent studies have proposed intelligent theories in renewable energy systems to address this question. For example, Yau et al. [16] used fuzzy theory to deal with the MPPT of the controller in a PV Generation System. In this study extension theory $[9,17]$ is applied to determine the intelligent selection of parameter $\sigma$ to reduce the amount of 
high frequency switching and high frequency noise in the MPP steady state. A flow chart for such a scheme is shown in Figure 7.

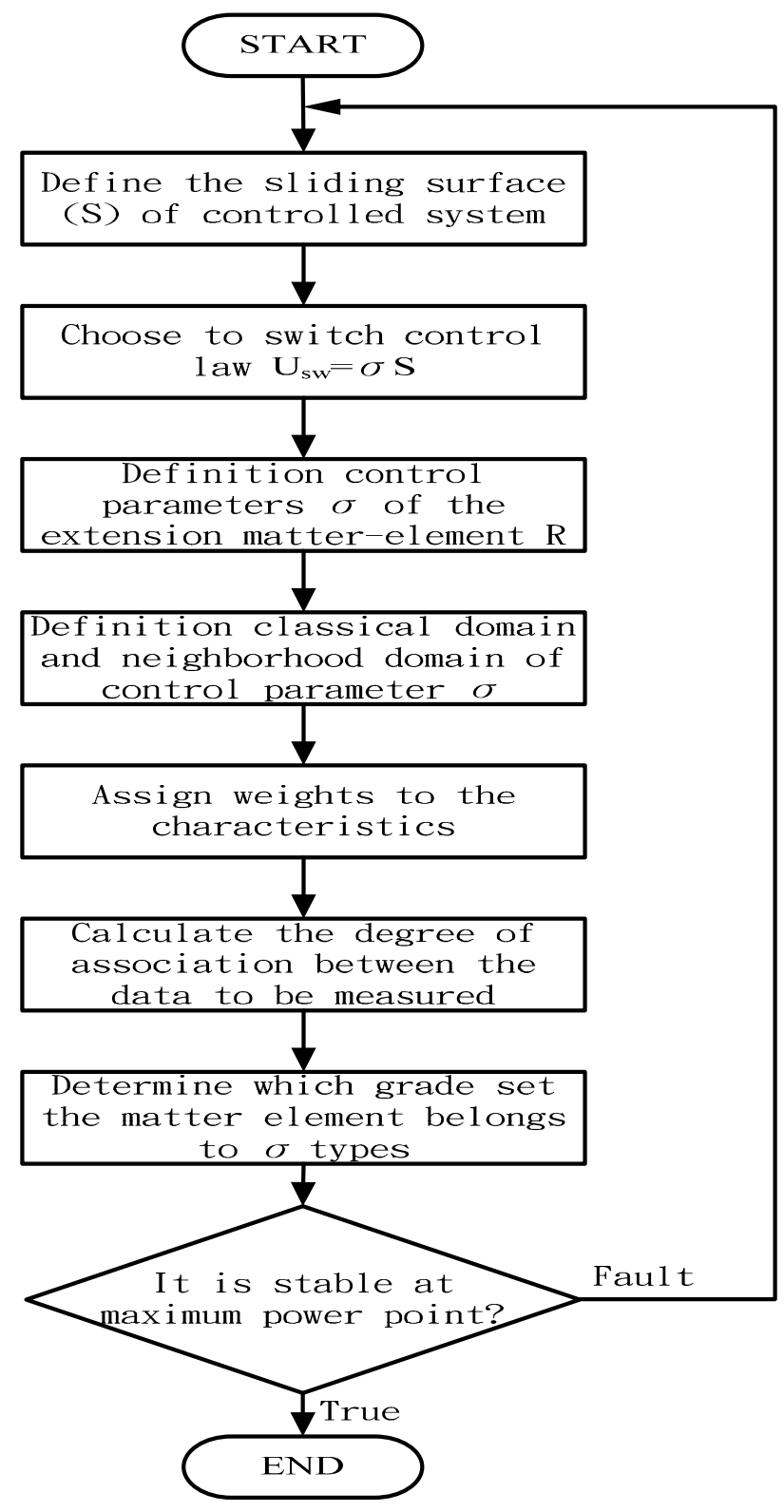

Figure 7. Extension Sliding Mode Control Flowchart of this scheme.

\section{Simulation and Experimental Results}

PSIM was used to simulate three control modes, P\&O, SMS, and ESMS, to observe the generator characteristics (and prepare the curves) of the maximum power output of the bike power generation system used in this study. Figure 8 shows the characteristic relationship between converter output power Po and output voltage Vo at different speeds. Figure 9a-c show the P\&O, SMS, and ESMS converter output power Po and output voltage waveform Vo, at speeds of $7.5 \mathrm{Km} / \mathrm{H}$ and $12 \mathrm{Km} / \mathrm{H}$. Figure 10 shows the power output from the three control modes at a speed of $7.5 \mathrm{Km} / \mathrm{H}$. Table 1 shows that the ESMS used in this paper has both high response speed and power output. 


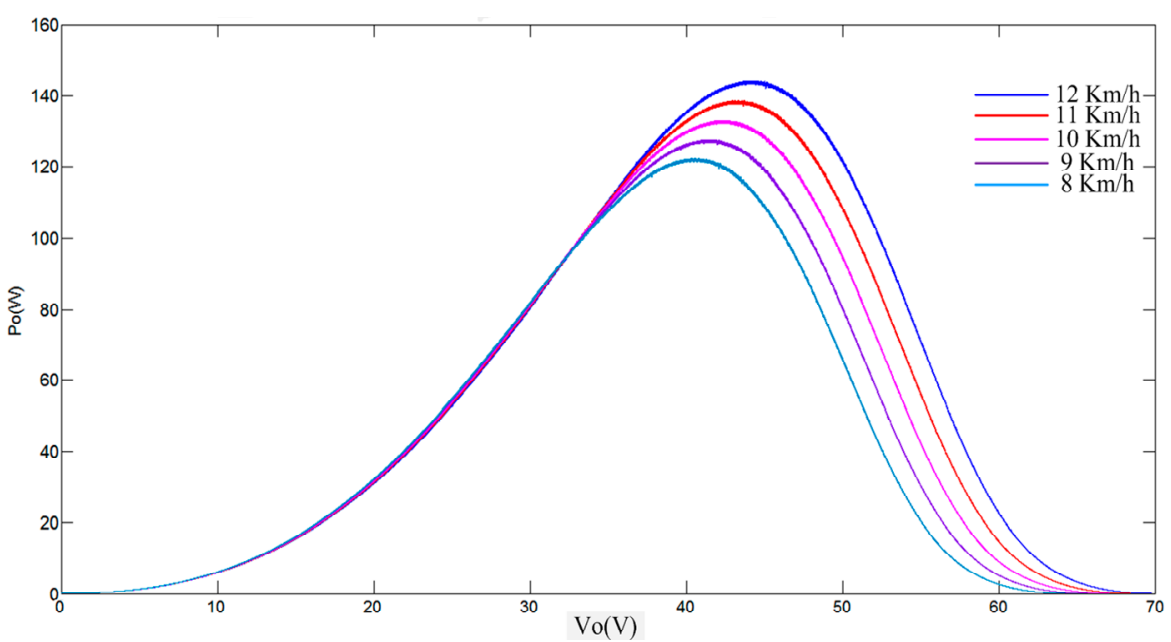

Figure 8. Simulated generator P-V characteristics curve.

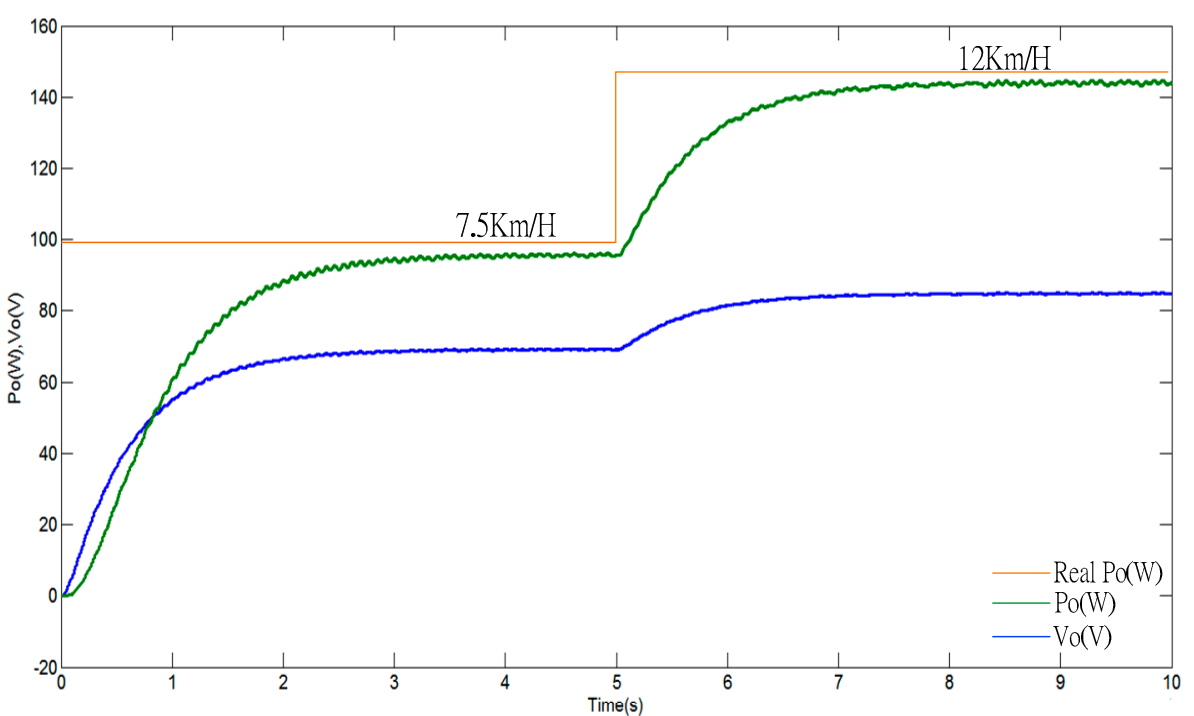

(a)

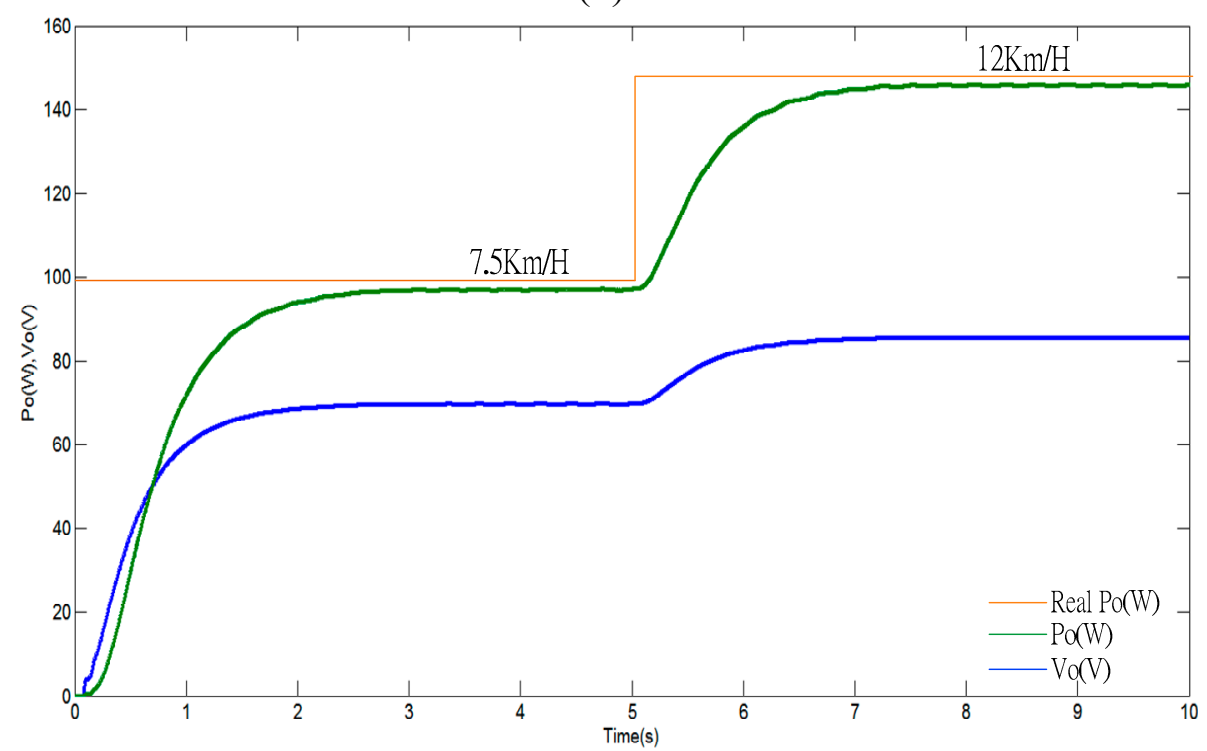

(b)

Figure 9. Cont. 


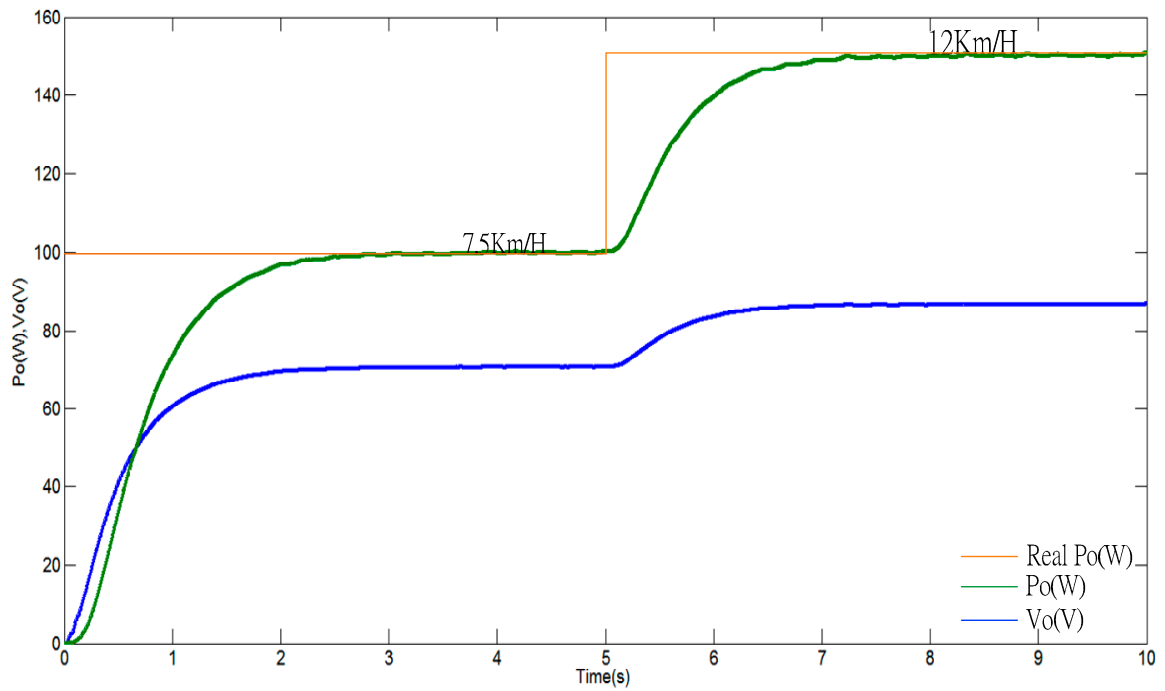

(c)

Figure 9. (a) $\mathrm{P} \& \mathrm{O}$ at a speed of $7.5 \mathrm{Km} / \mathrm{H}$ and $12 \mathrm{Km} / \mathrm{H}$; (b) $\mathrm{SMS}$ at a speed of $7.5 \mathrm{Km} / \mathrm{H}$ and $12 \mathrm{Km} / \mathrm{H}$; (c) ESMS at a speed of $7.5 \mathrm{Km} / \mathrm{H}$ and $12 \mathrm{Km} / \mathrm{H}$.

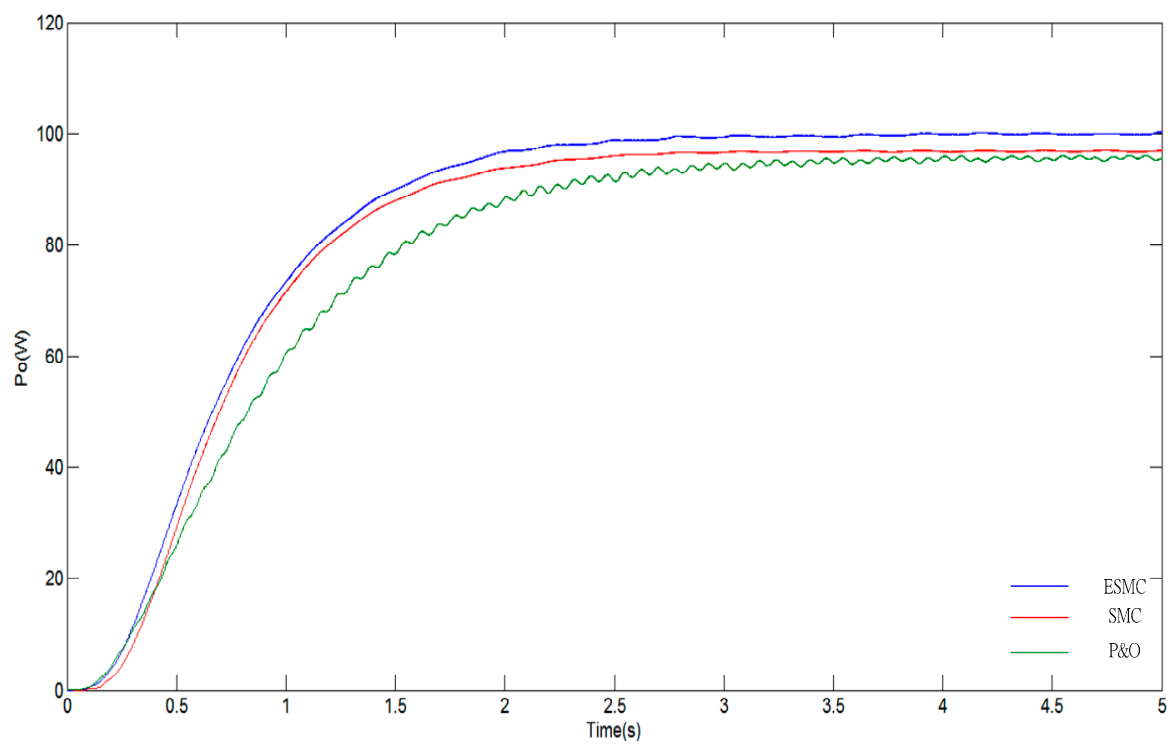

Figure 10. Output power of the three control modes.

Table 1. Characteristics of the three control modes.

\begin{tabular}{cccc}
\hline Methods & P\&O & SMS & ESMS \\
\hline System Properties & & & $96.78 \%$ \\
Conversion efficiency $\eta(\%)$ & $93.83 \%$ & 3.27 & $99.53 \%$ \\
Response speed Time (s) & 3.55 & 96.78 & 2.77 \\
Output power Po (W) at 7.5Km/H & 93.83 & 100 & 99.53 \\
Input power Pi (W) & 100 & 100 \\
\hline
\end{tabular}

Figure 11 shows the experimental configuration of maximum power tracking control. A resistance divider and Hall Element were used in the experiment. The Arduino Mega 2560 (Ivrea, Italy) captures 
voltage and current data for MPPT control calculation and transmits the PWM signal to the boost converter. Table 2 shows the generator specifications. Figure $12 \mathrm{a}-\mathrm{c}$ show the output voltage Vo and output current waveform Io of the three control modes. Figure 13 shows the P-V characteristics curve of the actual generator at a speed of $12 \mathrm{Km} / \mathrm{H}$ using ESMS MPPT control. Figure 14 shows the actual rotation speed of the generator, the speed is fixed at $12 \mathrm{Km} / \mathrm{H}$, converted into an angular-rate of about $\omega=100 \mathrm{rad} / \mathrm{s}$. Figure 15 shows the output power Po of the three control modes. Figure 15 compares the ESMS proposed in this paper with SMS and P\&O. It was found that ESMS has a higher tracking response speed, and effectively reduces the noise from high frequency SMS switching. To verify the validity the robustness and stability of this scheme, the experimental results with white noise as external disturbance angular and speeds from $\omega=100 \mathrm{rad} / \mathrm{s}$ to $\omega=118.83 \mathrm{rad} / \mathrm{s}$ are shown in Figure 16. It can be seen that the system can rapidly track change of angular speed $\omega_{t o}$ MPPT under external disturbance and the experimental results prove the effectiveness and validity of the method.

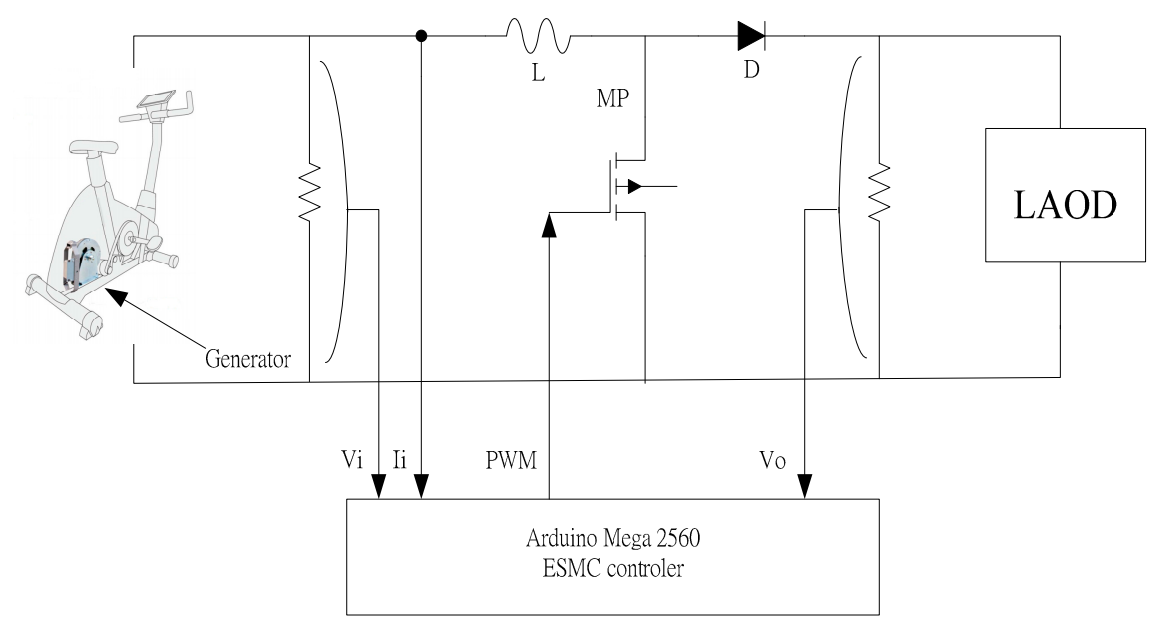

Figure 11. Actual circuit architecture.

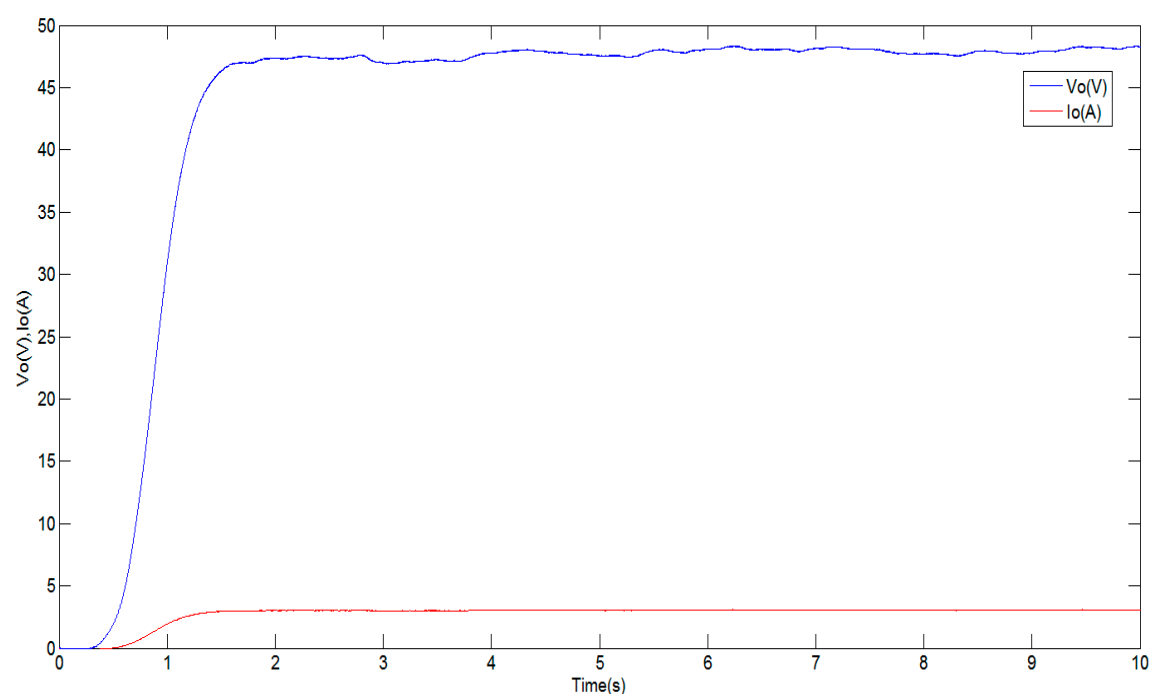

(a)

Figure 12. Cont. 


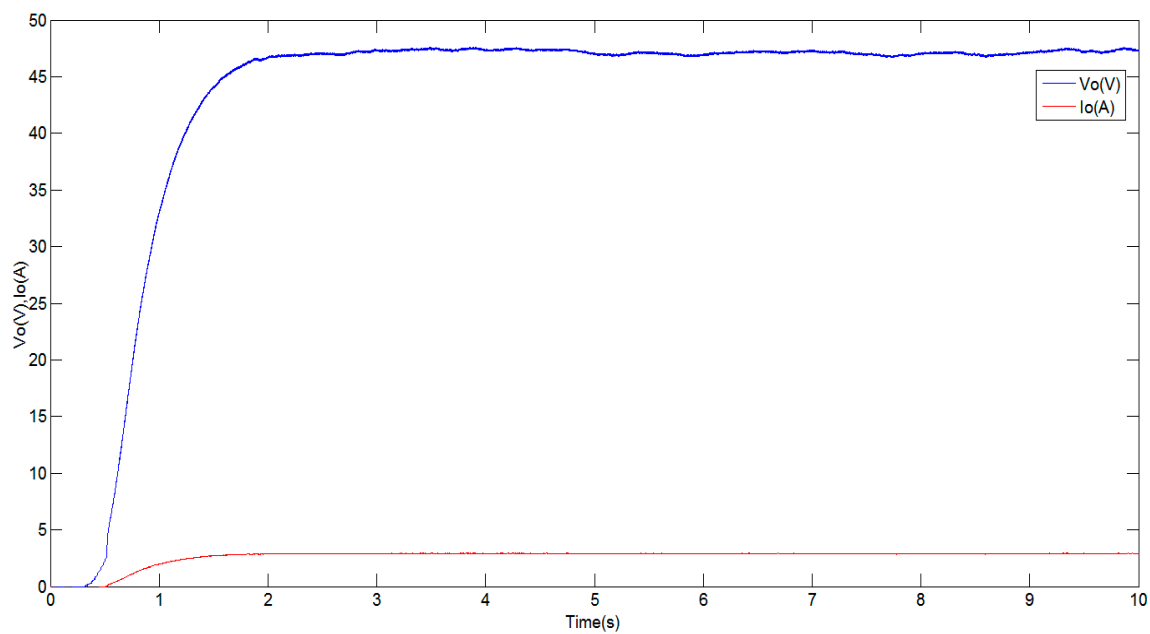

(b)

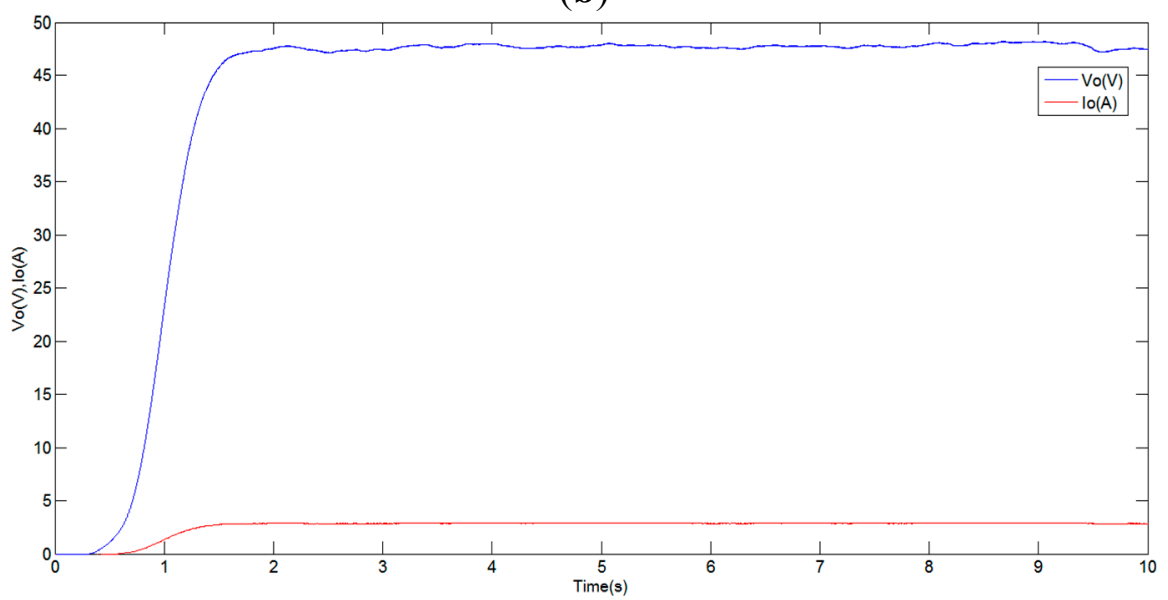

(c)

Figure 12. (a)ESMS output voltage (Vo) and current (Io); (b) SMS output voltage (Vo) and current (Io); (c) P\&O control output voltage (Vo) and current (Io).

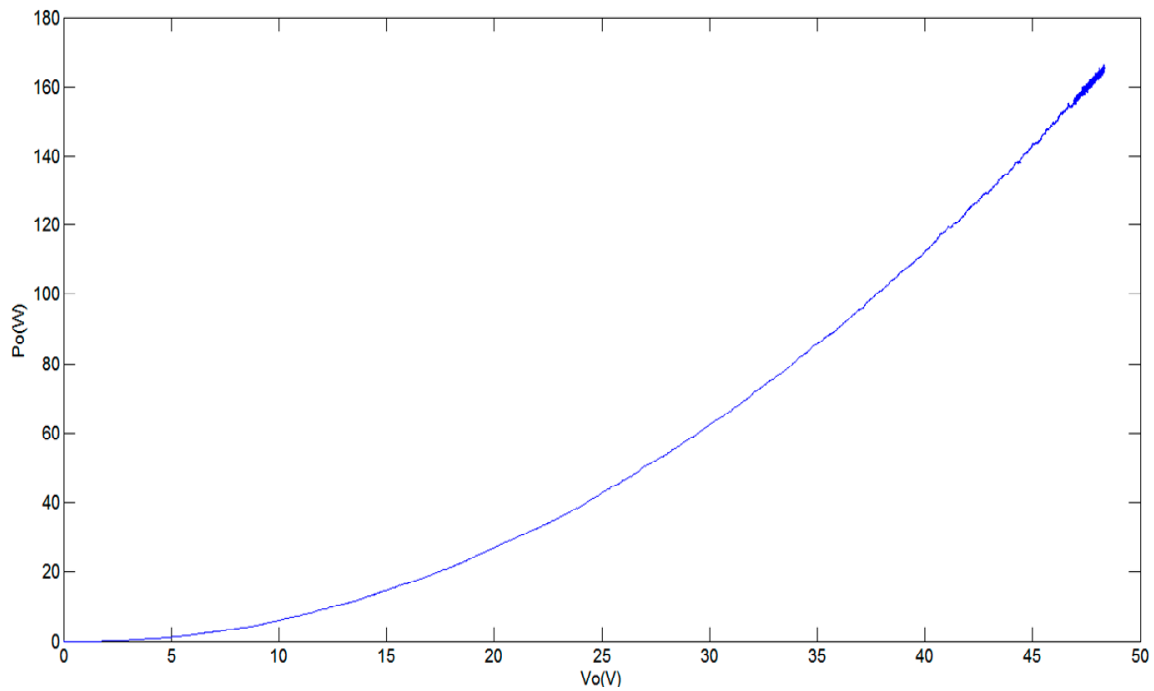

Figure 13. ESMS MPPT P-V characteristics curve. 


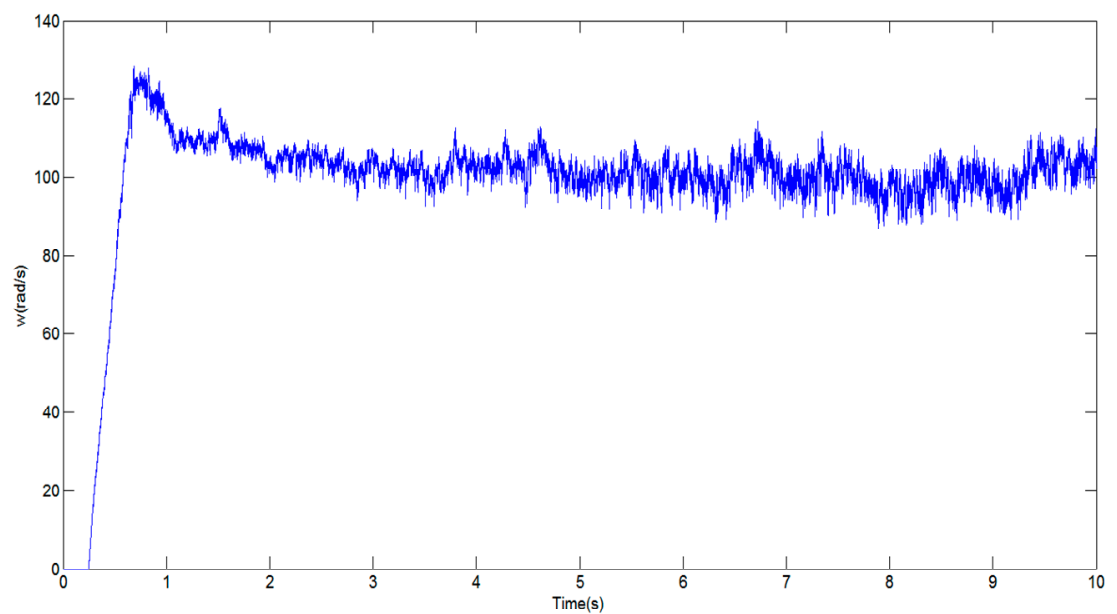

Figure 14. Rotation speed $\omega(\mathrm{rad} / \mathrm{s})$.

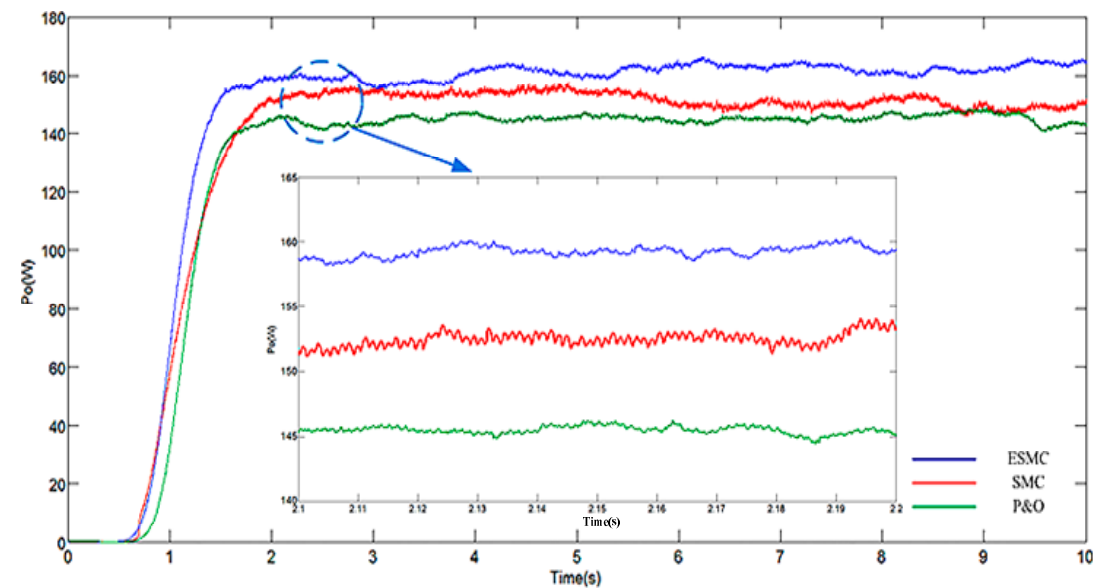

Figure 15. Experimental output power of the three control modes.

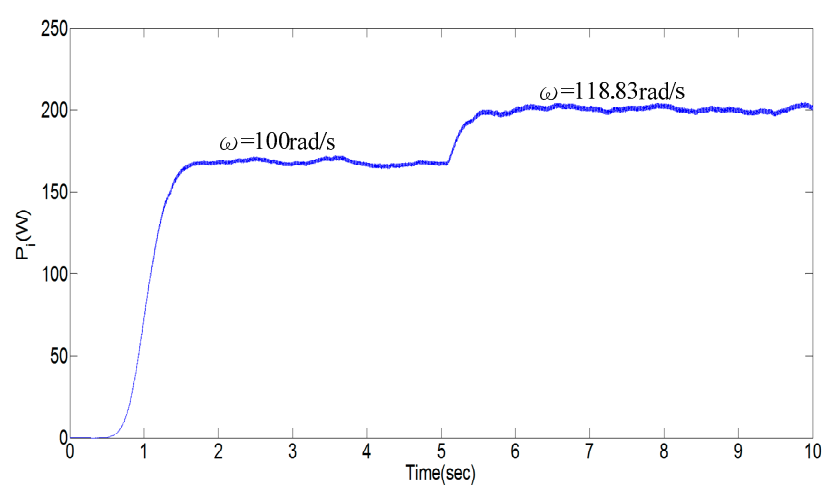

(a)

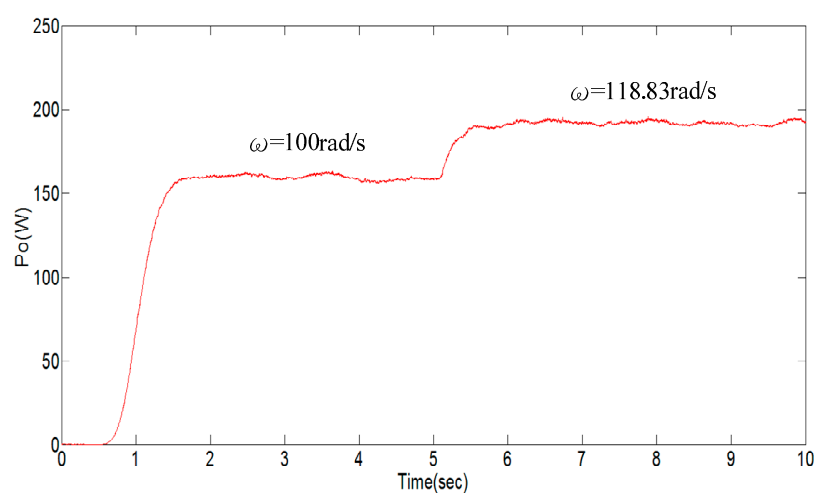

(b)

Figure 16. Stability and robustness verify at speeds from $\omega=100 \mathrm{rad} / \mathrm{s}$ to $\omega=118.83 \mathrm{rad} / \mathrm{s}$ with white noise: (a) Boost converter input power (Pi); (b) Boost converter output power (Po). 
Table 2. Generator specifications.

\begin{tabular}{cc}
\hline Voltage Specification & $220 \mathrm{~V}$ \\
Rated Power & $200 \mathrm{~W}$ \\
Peak Power & $500 \mathrm{~W}$ \\
Rated Speed & $1500 \mathrm{rpm}$ \\
Alternator Efficiency & $\geq 90 \%$ \\
Pole P & $4 \mathrm{P}$ \\
Armature Winding Ra & $6.26 \Omega$ \\
Coil Inductance Lm & $0.04 \mathrm{mH}$ \\
\hline
\end{tabular}

\section{Conclusions}

This study successfully used SMS for MPPT control of a human power generation system and also eliminated the need for an electronic switching component in sliding conditions. By applying the extension theory of intelligent logic calculus, the gain constant $\sigma$ could be adjusted to avoid converter component failure from high speed switching as well as high frequency noise interference to the system. The experimental and simulation results show the proposed method is robust and can control generation at different rotation speeds at the MPP. MPP is also rapidly stabilized when the generator speed changes. In addition, the MPPT of ESMS has better transient response and higher output power than SMS and $\mathrm{P} \& \mathrm{O}$.

\section{Acknowledgments}

The authors would like to thank the Ministry of science and Technology, Taiwan, for financially supporting this research under Contract No. MOST 104-2221-E-167-001 and MOST 103-2622-E-167-007-CC3.

\section{Author Contributions}

All authors have worked on this manuscript together and all authors have read and approved the final manuscript.

\section{Conflicts of Interest}

The authors declare no conflicts of interest.

\section{References}

1. Hua, C.C.; Cheng, C.H. Design and Implementation of Power Converters for Wind Energy Conversion System. In Proceedings of the Power Electronics Conference (IPEC), Sapporo, Japan, 21-24 June 2010.

2. Naci, G.; Ires, I. An improved soft switched PWM interleaved boost AC-DC converter. Energy Convers. Manag. 2011, 52, 403-413.

3. Knshnan, R.; Rim, G.H. Modeling, simulation, and analysis of variable-speed constant frequency power conversion scheme with a permanent magnet brushless DC generator. IEEE Trans. Ind. Electron. 1990, 37, 291-296. 
4. Knight, A.M.; Peters, G.E. Simple wind energy controller for an expanded operating range. IEEE Trans. Energy Convers. 2005, 20, 459-466.

5. Dehghan, S.M.; Mohamadian, M.; Varhani, A.Y. A New Variable-Speed Wind Energy conversion System Using Permanent-Magnet Synchronous Generator and Z-Source Inverte. IEEE Trans. Energy Convers. 2009, 24, 714-724.

6. Liu, Y.; Li, M.; Ji, X.; Luo, X.; Wang, M.; Zhang, Y. A comparative study of the maximum power point tracking methods for PV systems. Energy Convers. Manag. 2014, 85, 809-816.

7. Fu, D.; Xing, Y.; Ma, Y. MPPT of VSCF Wind Energy Conversion System Using Extremum Control Strategy. In Proceedings of the World Non-Grid-Connected Wind Power and Energy Conference (WNWEC), Nanjing, China, 5-7 November 2010.

8. Tao, C.W.; Taur, J.S.; Chan, M.L. Adaptive fuzzy terminal sliding mode controller for linear systems with mismatched time-varying uncertainties. IEEE Trans. Syst. 2004, 34, 255-262.

9. Wang, M.H. Extension neural network-type 2 and its applications. IEEE Trans. Neural Netw. 2005, $16,1352-1361$.

10. Chang, T.Y.; Pan, C.T.; Hsiao, C.C. A Novel Three-Phase Boost Type ac/dc Converter for BLDC Wind Power Generation Systems. In Proceedings of the Taiwan Power Electronics Conference (TWEC), Chiayi, Taiwan, 3 September 2010.

11. Zhang, X.Z.; Wang, Y.N. A novel position-sensorless control method for brushless DC motors. Energy Convers. Manag. 2011, 52, 1669-1676.

12. Chang, T.Y.; Pan, C.T.; Fang, E. A low voltage high current EV drive using inverter low side switches as current sensors, Power Electronics and Drive Systems (PEDS), Taipei, Taiwan, 2-5 November 2009.

13. Erickson, R.W.; Maksimovic, D. Fundamentals of Power Electronics, 2nd ed.; Springer: New York, NY, USA, 2001.

14. Chu, C.C.; Chen, C.L. Robust maximum power point tracking method for photovoltaic cells: A sliding mode control approach. Sol. Energy 2009, 83, 1370-1378.

15. Yau, H.T.; Chen, C.L. Fuzzy sliding mode controller design for maximum power point tracking control of a solar energy system. Trans. Inst. Meas. Control. 2012, 34, 557-565.

16. Utkin, V.; Guldner, J.; Shi, J. Sliding Modes in Electromechanical Systems; Taylor \& Francis: London, UK, 1999.

17. Wang, M.H.; Yau, H.T.; Wang, T.Y. Extension sliding mode controller for maximum power point tracking of hydrogen fuel cells. Abstr. Appl. Anal. 2013, 2013, 371064.

(C) 2015 by the authors; licensee MDPI, Basel, Switzerland. This article is an open access article distributed under the terms and conditions of the Creative Commons Attribution license (http://creativecommons.org/licenses/by/4.0/). 